\title{
ADAPTIVE FUZZY CONTROL FOR INDUCTION MOTOR DTC WITH ON LINE STATOR RESISTANCE DETECTION
}

\author{
M.M.A. Mahfouz, Mohamed Mahmoud Ismail \\ Faculty of Engineering, Helwan, Helwan University \\ E-Mail:mohamed.mahfouz@yahoo.co.uk
}

\begin{abstract}
Direct torque control (DTC) of an induction motor fed by a voltage source inverter is a simple scheme that does not need long computation time. The main advantage of DTC technique is that it is not sensitive to the variation of motor parameters except the stator resistance in its flux observer especially at low speed operation. The stator resistance can be changes during the motor operation due to ambient temperature or frequency. This paper, introduces an additional on Line fuzzy controller used to estimate the stator resistance for the DTC flux observer. The inputs for the proposed fuzzy controller are speed and stator current errors between the traditional DTC flux observer values, which using constant value of the stator resistance equals to the nominal value, and their values using the proposed on line stator resistance estimator values. The induction motor saturated pi model is used which is more practical than the approximate linear model especially in the large motors. The saturation function and the motor parameters are identified experimentally. The proposed technique response is checked at sinusoidal and trapezoidal reference speeds. The results show good improvements of the DTC response using the proposed adaptive fuzzy controller during on line variation in the stator resistance of the induction motor.
\end{abstract}

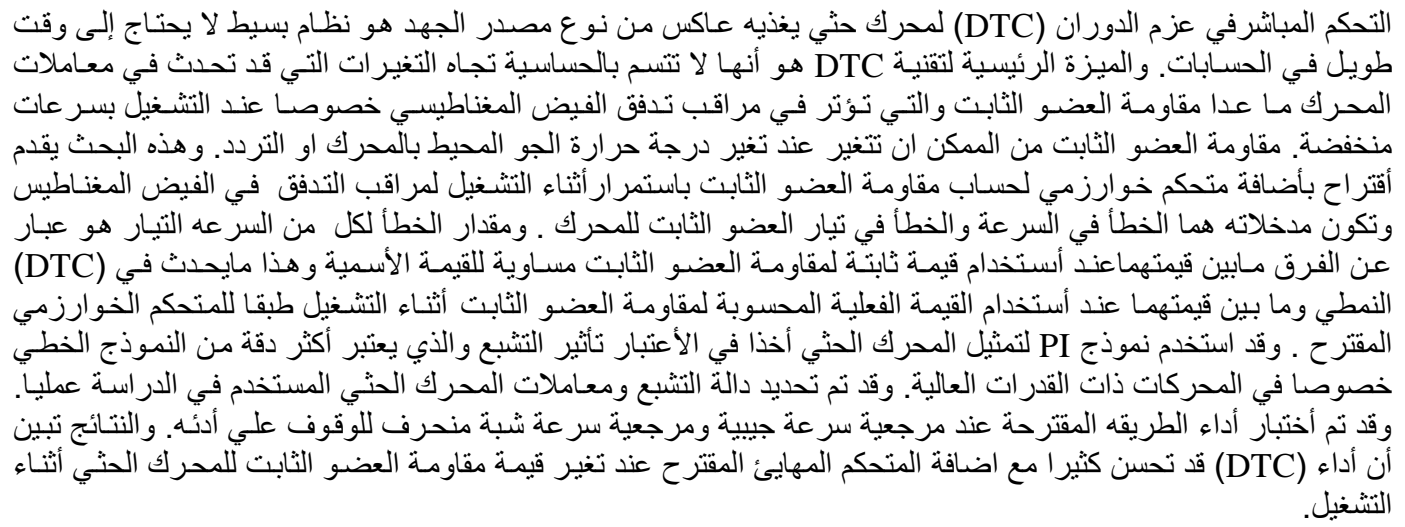

Keywords: Adaptive control, Fuzzy controller, DTC drives, Induction machines, Parameter estimation.

\section{INTRODUCTION}

In recent years significant advance have been made on the sensor less field oriented controlled induction machines drives. In the middle of 1980 direct torque control was developed as an alternative to field oriented control to overcome its problems [1]. In direct torque controlled (DTC) induction motor drive supplied by a voltage source inverter, the scheme as the name indicates, it is possible to control directly the stator flux linkage rotor flux or the magnetization flux and the electromagnetic torque by selecting of an optimum inverter voltage vector through a predesigned inverter gate pulses look-up tables [2]. The stator flux and electromagnetic torque are controlled in a closed loop by using flux and torque hysteresis comparators. Then, the selection of the optimum voltage vector of a voltage source inverter is to restrict the flux and torque errors within their respective flux and torque hysteresis comparator 
bands to obtain fast torque response, low inverter switching frequency and low harmonic losses [3]. Unlike field oriented control method, DTC techniques require utilization of hysteresis band comparators instead of flux and torque controllers. In addition, utilization of look-up tables to select inverter switching gate pulses is to replace the coordinate transformation and pulse width modulation (PWM) signal generators of field oriented control [4]. Before explaining the control principals of DTC we will first develop a torque expression as a function of the stator and rotor fluxes. Two level voltage source inverter or six step voltage inverter schematic is the most commonly used in DTC of induction motor. Recently, there are many topologies for the voltage source inverter used in DTC of induction motors as three level voltage source inverter that enhance the output voltage vector possibilities since more voltage inverter states are available. The DC supply to the inverter is provided either by a battery or a rectifier supplied from three phase AC source. Usually there is no neutral load connection between the motor and the inverter, the inverter output voltage (phase to neutral) is only dependant on the DC voltage link supplying the inverter (E) and the Boolean states of the inverter branches $\mathrm{Sa}, \mathrm{Sb}$ and $\mathrm{Sc}$ as given in equation (1) [5].

$$
\left[\begin{array}{l}
\mathrm{V}_{\mathrm{an}} \\
\mathrm{V}_{\mathrm{bn}} \\
\mathrm{V}_{\mathrm{cn}}
\end{array}\right]=\frac{\mathrm{E}}{3}\left[\begin{array}{ccc}
2 & -1 & -1 \\
-1 & 2 & -1 \\
-1 & -1 & 2
\end{array}\right]\left[\begin{array}{l}
\mathrm{S}_{\mathrm{a}} \\
\mathrm{S}_{\mathrm{b}} \\
\mathrm{S}_{\mathrm{c}}
\end{array}\right]
$$

The status of each inverter branch can be represented by two Boolean states 0 or 1 and considering the combinations of status of phases $a, b$ and $c$, there are eight admissible combination of the three pairs of switches groups. Accordingly the resulting space voltage vector driving the motor has eight possible positions or values. Two of these positions are null vectors, and correspond to the three upper switches closed, $\mathrm{V}_{7}\left(\begin{array}{lll}1 & 1 & 1\end{array}\right)$, or three lower switches are closed, $\mathrm{V}_{0}\left(\begin{array}{lll}0 & 0 & 0\end{array}\right)$ [6]. The remaining six positions are the active (non null) values of the space voltage vectors. The amplitude of the space voltage vectors depends only on the value of the DC link voltage. The six active space voltage vectors have the same amplitude equal to (2E/3) with regular phase angle of $60^{\circ}$, which are dividing the plan into six regular sectors (each $60^{\circ}$ angle wide) and each of them lies in the center of a sector of $60^{\circ}$ width named $S_{1}$ to $S_{6}$. The stator resistance voltage drop at high speed is very small which can be neglected but at low speed this approximation is not valid because stator resistance voltage drop take a significant portion compared with the input stator voltage accordingly, it has to be taken into consideration and be properly compensated [7].
In this paper, an adaptive on line estimator for the stator resistance value using fuzzy scheme is proposed to enhance the DTC flux observer accuracy and reliability using the speed and stator current errors. DTC stator flux observer principles are discussed to present the effect of stator resistance value on the DTC drive motor behavior. Also the saturation pi model parameters and saturation function are identified experimentally. The proposed on- line fuzzy scheme is presented and the simulation results are demonstrated.

\section{DTC STATOR FLUX OBSERVER}

The basic idea of the DTC concept is to choose the best voltage vector, which makes the stator flux rotates and produce the desired torque in a predefined band [8]. The DTC has the advantage that it is based on estimation of the instantaneous values of the flux and torque from stator variables only which are easily measurable. Most of the flux estimation techniques proposed is based on voltage model and current model or the combination of both, but both methods still have some drawbacks [8]. DTC technique can be used for speed control of three phase induction motors by adding an external speed control loop to the main core of the DTC. In such technique the motor speed is compared with reference speed then the resulting speed error is controlled by a PI speed controller in order to get fast speed response. The output of the PI controller used as a torque reference for the hysteresis torque comparator. The DTC with conventional stator resistance estimator is shown at Fig.1. The better accuracy in stator flux estimation can be achieved using modern flux observers instead of conventional flux estimators. Flux observers need a higher speed digital signal processor DSP or micro controller because of their high computation burden compared with other methods of flux estimators, but they are less sensitive to motor parameters variations. The reference values of the stator flux $\hat{\psi}_{s}{ }^{*}$ and electromagnetic torque $T_{e}{ }^{*}$ magnitudes are compared with their respective estimated values and the torque and flux errors are processed through three level and two level hysteresis band controllers. Usually the values of hysteresis band width are chosen to be within $\pm 2 \%$ to $\pm 6 \%$ of the reference values. These values shall be selected carefully, because of a too small values may have the effect of losing the control. Furthermore the flux hysteresis band mainly affects the stator current distortion, and the torque hysteresis band affects the switching frequency and thus the switching losses [3]. The output of both torque and flux hysteresis comparators $\left(H_{T e}, H_{\psi}\right)$ with the position of the stator flux are used as inputs 
to the voltage vector selection block to generate the appropriate control voltage vector for the inverter by a predesigned look-up table. The selection of the appropriate voltage vector is based on restricting the stator flux and electromagnetic torque errors within their respective hysteresis band width.

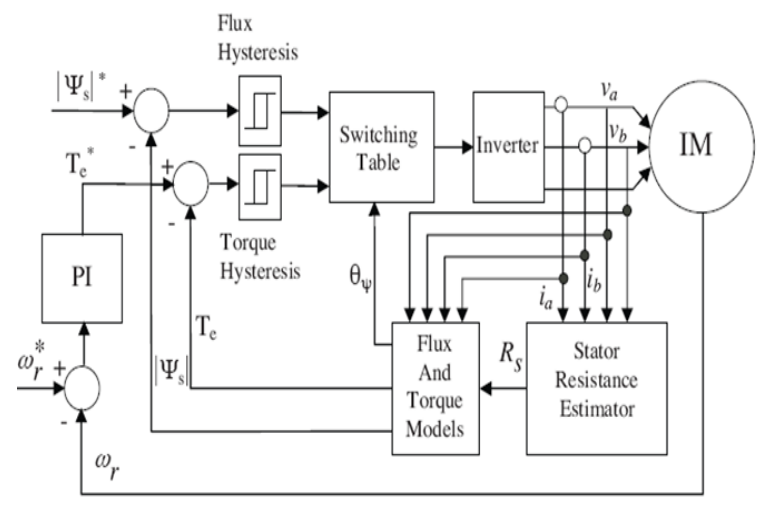

Fig. 1: DTC with Rs conventional estimator

\subsection{Effect of Stator Resistance}

The stator flux linkage can be expressed as [8\&3]:

$\hat{\psi}_{s}^{s}=\int\left(v_{s}(t)-R_{s} i_{s}\right) d t$

The stator flux is directly affected by impressing the stator voltage $V_{s}$ through the output of a voltage source inverter, which has only eight voltage vectors including six nonzero voltage vectors and two zero ones. Because of the stator flux changes discretely at the switching intervals and the applied voltage to the stator is one of the $8^{\text {th }}$ voltage vectors of the two levels VSI. Therefore, equation (2) can be rearranged as:

$$
\hat{\psi}_{s}^{s}=\hat{\mathrm{V}}_{\mathrm{s}}\left(S_{a}, S_{b}, S_{c}\right) \cdot \Delta t-\int R_{s} i_{s} d t+\hat{\psi}_{s o}{ }^{s}
$$

Where; $\hat{\psi}_{\text {so }}{ }^{s}, \hat{\psi}_{s}{ }^{s}$ are; stator flux values at the beginning and at the end of the inverter switching $\Delta \mathrm{t}$ period respectively. Eqn. (3) show that, the stator flux moves on a locus with constant velocity determined by the selected voltage vector and the duration $\Delta \mathrm{t}$ for which it is applied, therefore torque angle can be controlled by controlling the speed of rotation of the stator flux with respect to the rotor flux. This can be done by changing $\hat{\psi}_{s} s$ incrementally by applying proper stator voltage vector $\hat{V}_{s}$ for time increment $\Delta$ t. Eqn. (3) can be written as:

$$
\Delta \hat{\psi}_{s}{ }^{s}=\hat{\mathrm{V}}_{\mathrm{s}}\left(S_{a}, S_{b}, S_{c}\right) \cdot \Delta t-\int R_{s} i_{s} d t
$$

The variation of $R_{s}$ may influence the calculation of stator flux significantly and thereby the overall performance of the DTC system. At low speeds, the back emf term is small, and the resistive drop $R_{s} I_{s}$ is comparable with the supply voltage magnitude $V s$. Therefore any change in stator resistance gives wrong estimation of stator flux and consequently of the electric torque, stator current and the stator flux position. An error in stator flux position is more important as it can cause the controller to select a wrong switching state which can result in failure of the controller. So the parameter mismatch between the controller and motor makes the drive system unstable. So the stator resistance compensation is essential to overcome instability in DTC control [9].These make a sound to have a reliable on line stator resistance estimator to improve the DTC drive global performance which is the target of this paper.

\section{SATURATED INDUCTION MOTOR MODELING}

The main results of the dissertation on induction motor control under magnetic saturation will be based on the $\pi$-model in this paper as the $\pi$-model was experimentally found be better suited to capture the nonlinear magnetic effect, and furthermore it is much easier, as will appear shortly, to deal with in terms of nonlinear control law synthesis. The relationship between the currents and the fluxes for the $\pi$ model can be compactly written as [10]:

$$
\left[\begin{array}{c}
\mathrm{I}_{\mathrm{S}} \\
\mathrm{I}_{\mathrm{r}}
\end{array}\right]=\left[\begin{array}{cc}
\left(\mathrm{g}_{\mathrm{S}}\left(\left\|\psi_{\mathrm{s}}\right\|\right)+\mathrm{g}_{1}\right) \mathrm{I}_{2} & -\mathrm{g}_{1} \mathrm{I}_{2} \\
-\mathrm{g}_{1} \mathrm{I}_{2} & \left(\mathrm{~g}_{\mathrm{r}}\left(\left\|\psi_{\mathrm{s}}\right\|\right)+\mathrm{g}_{1}\right) \mathrm{I}_{2}
\end{array}\right]\left[\begin{array}{l}
\psi_{\mathrm{S}} \\
\psi_{\mathrm{r}}
\end{array}\right]
$$

Where; $I_{2}$ is the $2 \times 2$ identity matrix, $g_{1}$ is the reciprocal of the leakage inductance $\left(\mathrm{L}_{l}\right), \mathrm{g}_{\mathrm{s}}$ and $\mathrm{g}_{\mathrm{r}}$ are the stator and rotor vector-valued nonlinear saturation functions. The scalar saturation functions $\mathrm{g}_{\mathrm{s}}$ and $\mathrm{g}_{\mathrm{r}}$ only affect the magnitude, while keeping flux and current at same direction. These functions are monotone increasing and are non zero at the origin. The saturation functions $g_{s}(x)$ and $g_{r}(x)$ have to be identified experimentally for each motor as shown in the next section.

\subsection{Motor Parameters and Saturation Function}

The parameters of the motor models used in this study are given in table (1) and were calculated experimentally from no load test and short circuit test. The saturation functions are determined from the no load test as the following;

$$
\begin{aligned}
& \mathbf{V}_{\mathbf{S}}=\mathbf{V}_{\mathbf{n} \mathbf{l}}-\mathbf{I}_{\mathbf{O}}\left(\mathbf{R}_{\mathrm{S}}+\mathbf{X}_{\mathrm{S}}\right) \\
& \mathbf{I}_{\mathrm{o}}=\mathbf{I}_{\mathbf{m}}
\end{aligned}
$$

The mutual inductance voltage equations are:

$$
\begin{aligned}
& \mathbf{V}_{\mathbf{s}}=\mathbf{J \omega}\left(\mathrm{g}(\mathbf{x}){ }^{*} \mathbf{I}_{\mathbf{m}}\right) \\
& \boldsymbol{\psi}_{\mathbf{m}}=\mathbf{g}(\mathbf{x}){ }^{*} \mathbf{I}_{\mathbf{m}}
\end{aligned}
$$$$
\text { The air gap flux equation is given by }
$$$$
\boldsymbol{H}_{\mathrm{m}}=\frac{V_{\mathrm{s}}}{2 \mathrm{II}}
$$

Where; $\mathrm{J}$ is the moment of inertia is the speed, $\mathrm{V}_{\mathrm{s}}$ is the stator voltage and it is calculated from measured no load voltage $\left(\mathrm{V}_{\mathrm{nl}}\right)$ and the no load current is $\left(\mathrm{I}_{\mathrm{o}}\right)$ 
using equation (7). From equations (8) and (9), the magnetization curve (relation between $\left(\psi_{\mathrm{m}}\right.$ and $\mathrm{I}_{\mathrm{m}}$ ) can be plotted as shown in Figure (2). From the magnetization curve, the magnetization function $\left(\psi_{\mathrm{m}}\right)$ as a function of $\left(\mathrm{I}_{\mathrm{m}}\right)$ can be obtained using curve fitting. If the mutual inductance is needed, it can be obtained by fitting the magnetization curve to a straight line passing through the origin. The stator saturation function is:

$$
\mathrm{g}_{\mathrm{S}}(\mathrm{x})=0.5455 \sinh (2 \mathrm{x})
$$

Similarly the rotor saturation function is:

$\mathrm{g}_{\mathbf{r}}(\mathrm{x})=0.5455 \sinh (2 \mathrm{x})$

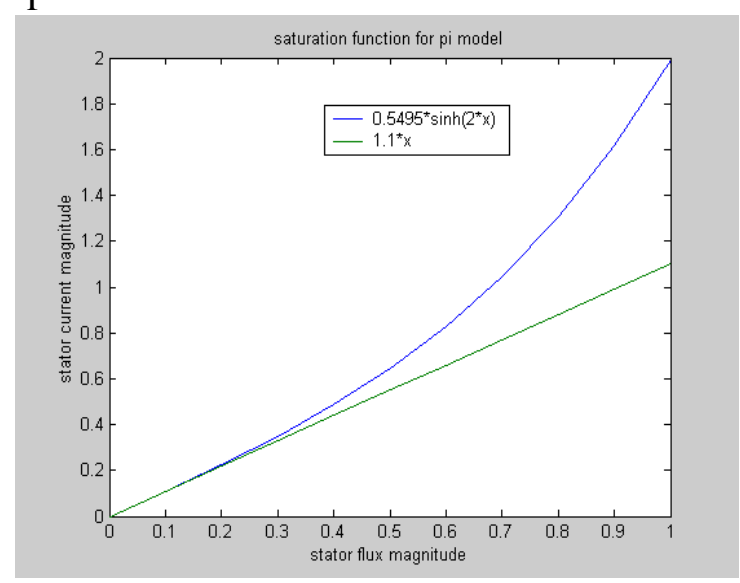

Fig.2: Non linear Saturation function compared to linear function.

Table (1) motor parameters

\begin{tabular}{c|c}
\hline Parameter(unit) & $\pi$-model \\
\hline $\mathrm{R}_{\mathrm{s}}(\Omega)$ & 8 \\
$\mathrm{R}_{\mathrm{r}}(\Omega)$ & 6 \\
$\mathrm{~L}_{\mathrm{m}}(\mathrm{H})$ & 1.1 \\
$\mathrm{~L}_{\mathrm{l}}(\mathrm{H})$ & 0.062 \\
$\mathrm{~J} \mathrm{Kgm}$ Kg $^{\prime}$ & 0.06 \\
b Ns/rad & 0.04 \\
\hline
\end{tabular}

\section{PROPOSED ADAPTIVE FUZZY CONTROLLER}

The procedure of implementing fuzzy logic controller is known as fuzzy logic inference system (FIS). Generally, there are three main fuzzy inference systems Mamdani fuzzy logic inference system, Sugeno fuzzy logic inference system, and Tsukamoto fuzzy logic inference system [10]. In this paper Mamdani fuzzy logic controller is used. The block diagram for the proposed fuzzy controller for online stator resistance adaptation of the flux observer for any variation in the stator resistance for induction motor is shown in Fig. 3. The inputs for the fuzzy controller are, errors between the measured values of the motor speed and the stator current $\left(\mathrm{I}_{\mathrm{s}}\right)$ and its estimated values $(\omega)$. The speed error is the difference between the speed reference $\left(\omega_{\text {ref }}\right)$ and actual speed $(\omega)$. While the stator current error is the difference between the stator current without adapting the stator resistance that mean at $R_{s}$ equal to $R_{s n}$ and the estimated current at ( $I_{s}$ estimated $)$ with adapting at $R_{S}$ equal $\left(R_{s \text { adaptive }}\right)$. The on line value of the stator resistance at each sampling time calculated as follows:

$$
R s(k)=R s(k-1)+\Delta R s(k)
$$

The speed error is:

$e_{\omega}(k)=\omega_{\text {ref }}-\omega(k)$

The stator current error is:

$e_{i}(k)=I_{s}-I_{\text {estimated }}(k)$

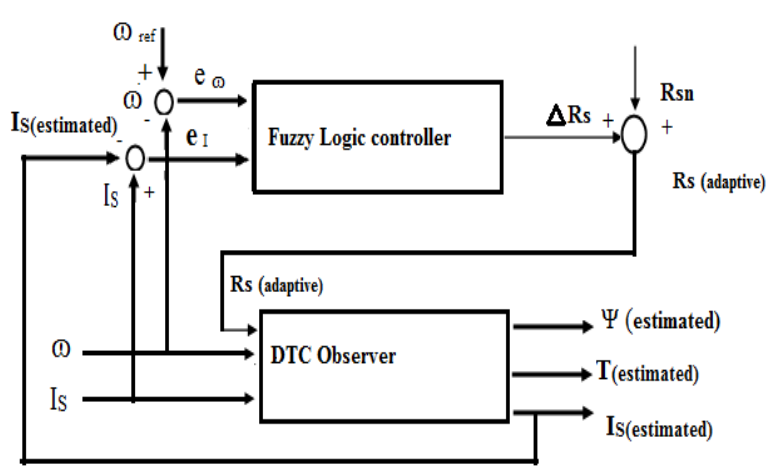

Fig 3: Proposed Fuzzy controller for Rs estimator

\section{SIMULATION RESULTS AND DISCUSSIONS}

The proposed system simulation was done by using SIMULINK and FUZZY toolboxes under MATLAB program. The motor parameters and the saturation functions that had been identified in the previous section experimentally were used in the study. The proposed DTC controller performance reliability was checked at different reference speeds.

\section{1: Sinusoidal Reference Speed, Case 1}

The simulation Conventional DTC motor speed is shown in Fig. 4a. The results illustrate that there is a small deviation between the actual motor speed and the reference speed during the increasing period (010) sec. After this period while the stator resistance value was $16 \mathrm{ohm}$, the actual motor speed with conventional DTC cannot reach its reference value and there was a significant difference between them, even in the speed direction. While Fig. 4.b shows the proposed fuzzy controller motor speed which illustrates that the actual speed and the reference speed are identical and the proposed fuzzy controller performance has a high reliability even with sinusoidal reference speed. 


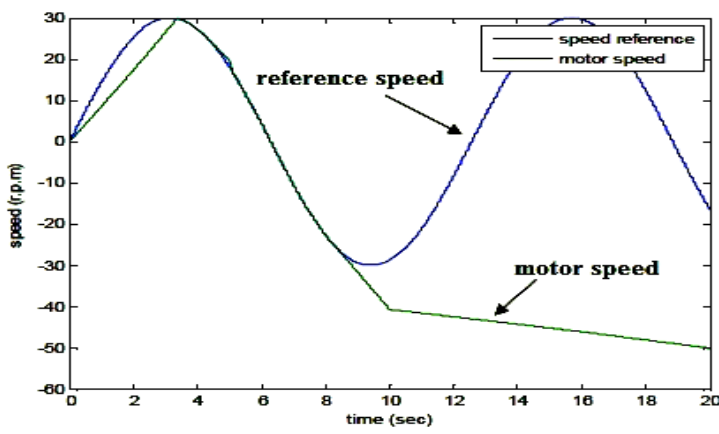

4. a: Speed at conventional DTC Speed ,case 1

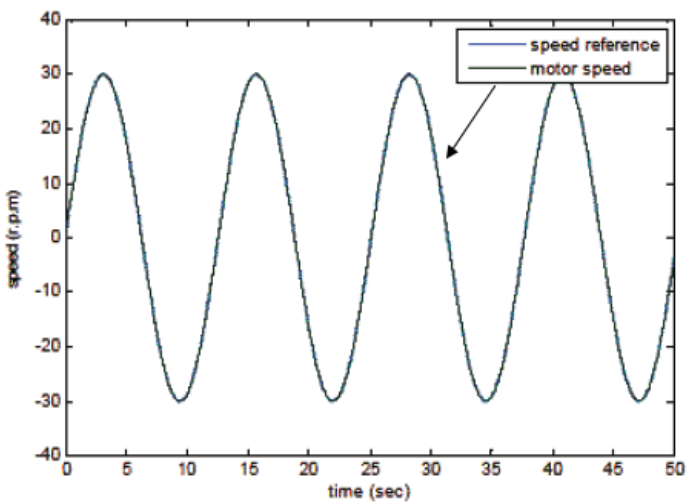

Fig. 4.b: Speed at Proposed Fuzzy DTC, case1

Rotor flux at conventional DTC is shown in Fig. 5.a as the reference value was at 0.4 Weber. It shows that the conventional DTC fails to fulfill the rotor flux reference during the increasing of the stator resistance as it keep the resistance value constant with its nominal value. The proposed fuzzy controller rotor flux is shown in Fig. 5.b which shows that the fuzzy controller succeed to adapt itself during the stator resistance change and keeping the rotor flux equal to the target reference value.

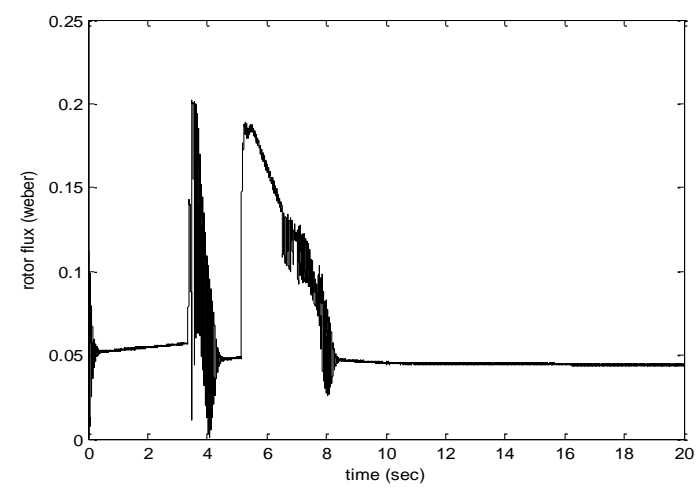

Fig 5.a: Rotor flux conventional DTC, case 1.

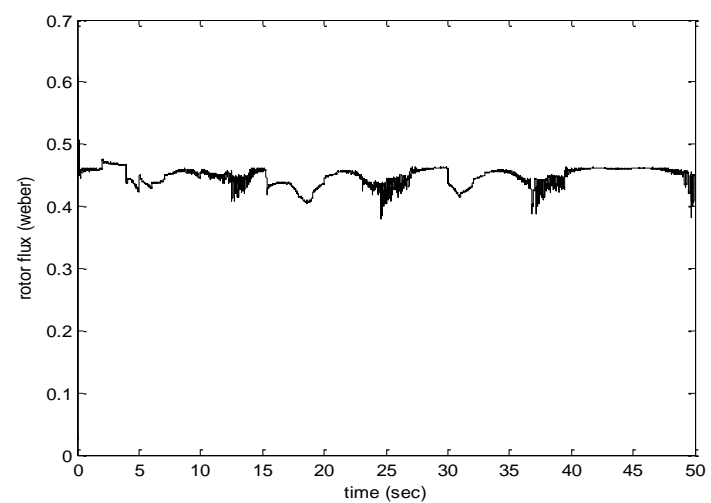

Fig.5.b: Rotor flux proposed Fuzzy, case 1.

Figure 6.a shows the stator current while Fig. 7.a shows the motor torque for the conventional DTC which illustrate that their values cannot match the speed change and its values are going down and then back as a constant and this is due to the difference between the reference speed and the actual motor speed and also due to rotor flux deviation. The proposed fuzzy controller stator current and torque in Fig. 6.b and Fig. 6.c respectively and it show that their values are stable, reliable and match the reference speed. The proposed fuzzy controller estimation for the stator resistance during the on line change of its value is shown in Fig. 8 which indicate that the proposed technique has a high sensitivity for the stator resistance change.

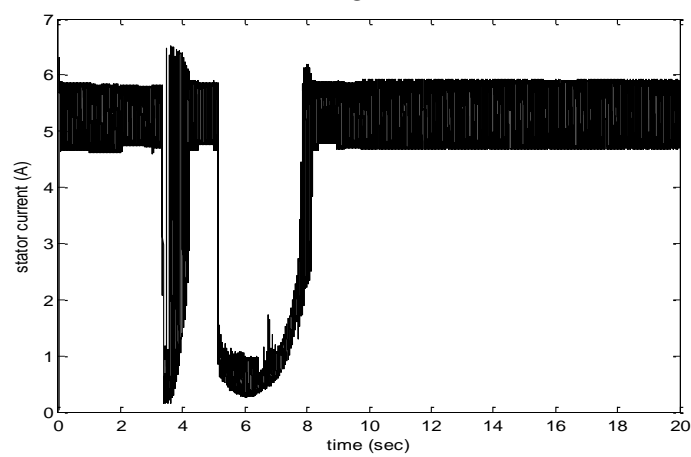

Fig 6.a: Stator current conventional DTC, case 1

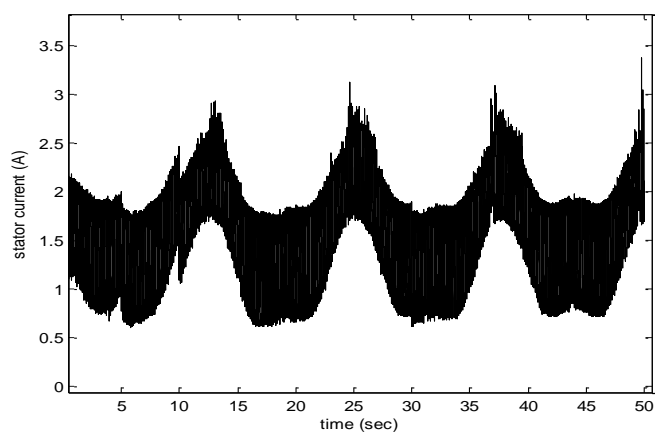

Fig.6.b: Stator current Proposed Fuzzy, case 1. 


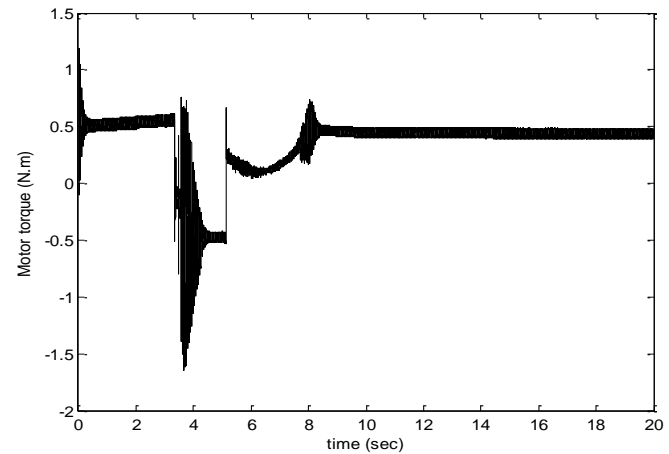

Fig 7.a: Torque conventional DTC, case1.

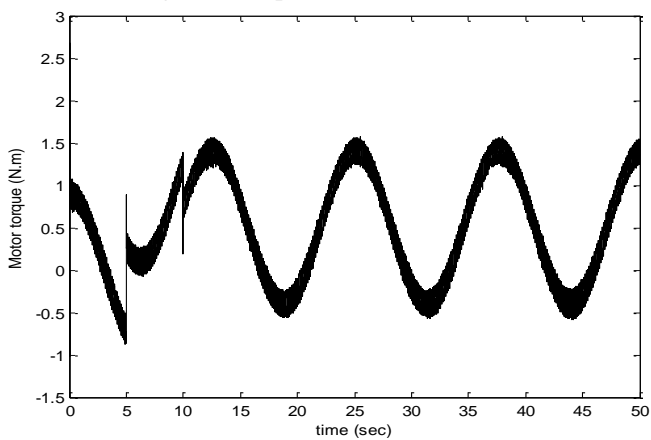

Fig.7.b: Torque proposed Fuzzy, case1.

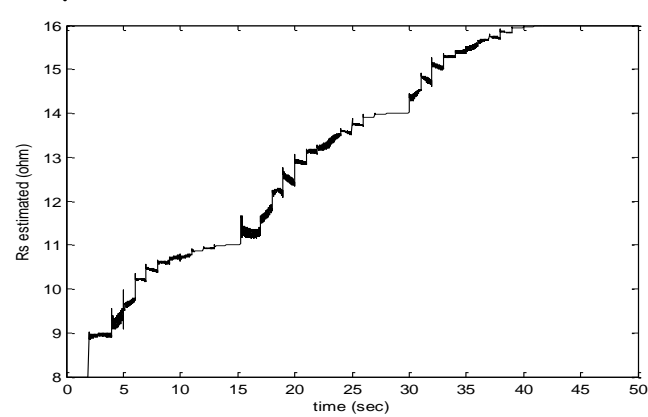

Fig.8: Proposed Fuzzy estimator stator resistance, case1.

\section{2: Trapezoidal Reference Speed, Case 2}

This case studies the reliability and sensitivity of the proposed fuzzy controller at trapezoidal reference speed during the on line increasing of the stator resistance with the same manner of case1. Simulation result for the proposed fuzzy controller motor speed is shown in Fig.9.a, it illustrates that the actual speed is tracked the reference speed during the stator resistance change period. Also the rotor flux of the proposed fuzzy controller rotor flux in this case is introduced at Fig. 9.b, which shows that it achieves the target reference values assigned by 0.4 Weber and adapt itself during the stator resistance change period with high sensitivity. The stator current and motor torque in this case are shown in Fig. 9.c and Fig. 9.d respectively which illustrate that their values are changed sensitively and matched the change of the motor speed and the stator resistance. Figure 10 shows the proposed fuzzy controller estimation output for the stator resistance during the on line change and it shows the high sensitivity of the proposed technique to reach the actual value of the stator resistance during the motor on line operation.

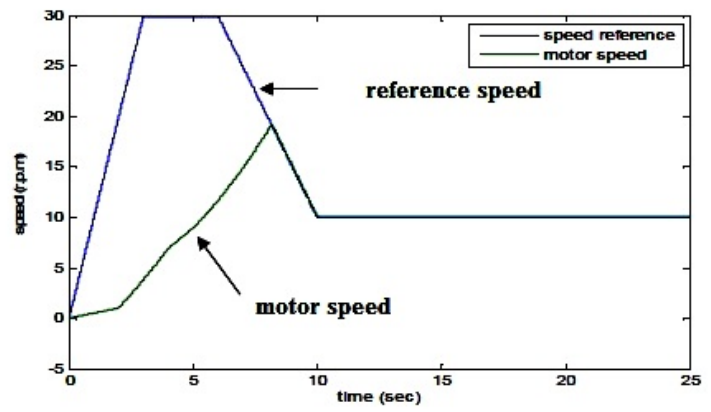

Fig.9.a: Proposed Fuzzy motor speed, case 2.

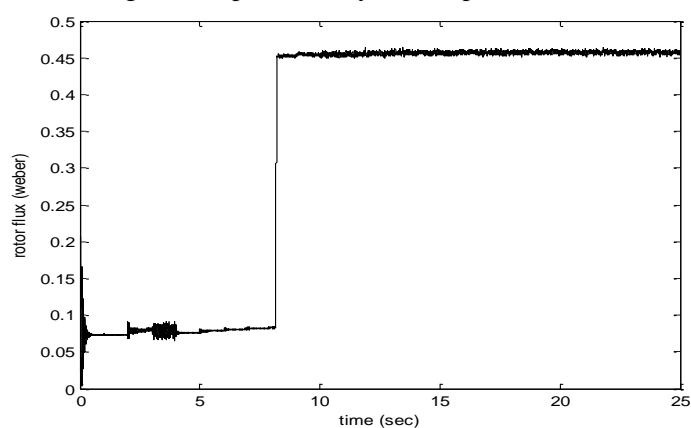

Fig.9.b: proposed Fuzzy rotor flux, case 2.

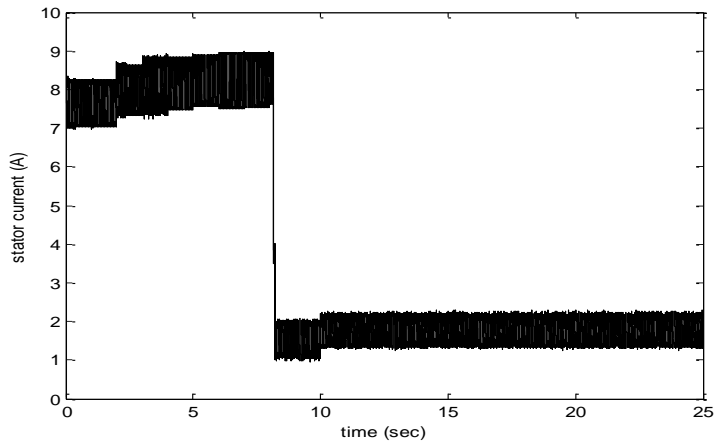

Fig.9.c: Proposed Fuzzy current, case 2.

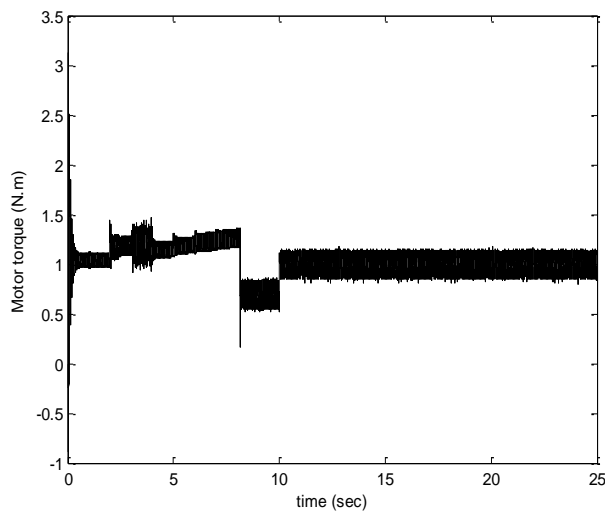

Fig.9.d: proposed Fuzzy torque, case 2 


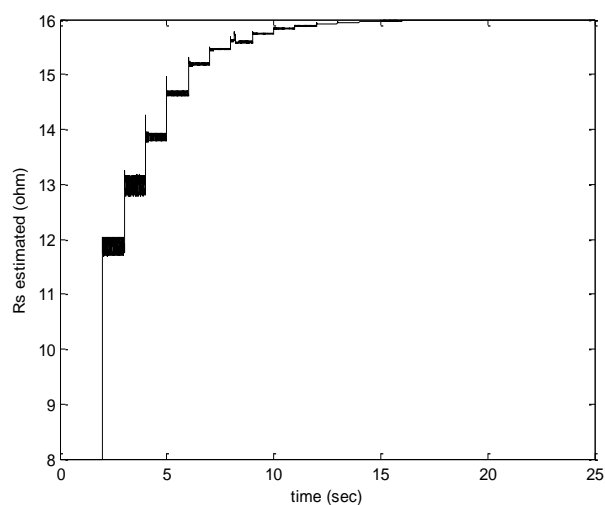

Fig.10: Proposed Fuzzy estimator of stator resistance, case2.

\section{CONCLUSION}

The stator resistance of the induction motor can be increased during the normal operation and this can be due to the increasing of the ambient temperature and/or overloading and /or increasing of the core losses or the motor original parameters are changed. The DTC flux observer causes a poor response of the controller during the variation in the stator resistance which may lead to instability of the control system. In this paper the saturated model of induction motor is used, and the saturation function and the motor parameters are identified experimentally. Also a fuzzy controller is proposed to be used for online adaptation of the stator resistance value for the flux observer. The results indicated that the proposed fuzzy controller improve the DTC performance during the on line change of the stator resistance. The proposed technique is simple and checked for both sinusoidal and trapezoidal reference speeds. The results show that the proposed system is reliable and sensitive and can be implemented for the DTC performance enhancement.

\section{REFERENCES}

Bimal K. Bose, "Modern Power Electronics and AC Drives", Published by Prentice Hall PTR, Upper Saddle River, New Jersey 2002.

[1] Zakdy Sorchini and Philip T. Krein, " Formal Derivation of Direct Torque Control for Induction Machines ", IEEE Trans. on Power Electronics. vol. 21, no. 5, September 2006, pp 1428- 1436.

[2] Domenico Casadei, Francesco Profumo Giovanni Serra, and Angelo Tani, " FOC and DTC: Two Viable Schemes for Induction Motors Torque Control ", IEEE Trans. on Power Electronics. vol. 17, no. 5, September 2002, pp 779- 787.

[3] A. Sapin,P.K. Steimerand J.Simond;" Modeling, Simulation, and Test of a Three-Level Voltage Source Inverter with Output LC Filter and Direct Torque Control ", IEEE Trans. on Industry
Applications. vol. 43, no. 2, March/April 2007, pp 469-475.

[4] Domenico Casadei, Giovanni Serra, and Angelo Tani, " Steady-State and Transient Performance Evaluation of a DTC Scheme in the Low Speed Range ", IEEE Trans. on Power Electronics. vol. 16, no. 6, November 2001, pp 846-851.

[5] Kuo-Kai Shyu, Li-Jen Shang, Hwang-Zhi Chen, and Ko-Wen Jwo, " Flux Compensated Direct Torque Control of Induction Motor Drives for Low Speed Operation ", IEEE Trans. on Power Electronics. vol. 19, no. 6, November 2004, pp 1608-1613.

[6] Yen-Shin Lai and Juo-Chiun Lin, " New Hybrid Fuzzy Controller for Direct Torque Control Induction Motor Drives ", IEEE Trans. on Power Electronics. vol. 18, no. 5, September 2003, pp 1211 - 1219.

[7] Fatiha Zidani and Rachid Nait Said, " Direct Torque Control of induction Motor with Fuzzy Minimization Torque Ripple ", Journal of Electrical Engineering. Vol. 56 no. 7-8, 2006, pp. 183-188.

[8] Milan Zalman and Ivica Kuric, " Direct Torque and Flux Control of Induction Machine and fuzzy controller ", Journal of Electrical Engineering. Vol. 56 no. 9-10, 2005, pp. 278-280.

[9] Luis Romeral, Antoni Arias, Emiliano Aldabas and Marcel. G. Jayne. " Novel Direct Torque Control (DTC) Scheme with Fuzzy Adaptive Torque Ripple Reduction", IEE Trans. on Industrial. Electronics, vol. No. 3, June 2003, pp. 487-492. 